\title{
Perinatal Mortality and Associated Risk Factors among Singleton Babies in Unguja Island, Zanzibar
}

\author{
Rukia Rajab Bakar ${ }^{1,2,3}{ }^{*}$, Rachel N. Manongi1,2, Blandina T. Mmbaga1,4,5, Birgitte Bruun Nielsen ${ }^{6}$ \\ ${ }^{1}$ Kilimanjaro Christian Medical University College, Tumaini University, Moshi, Tanzania \\ ${ }^{2}$ Institute of Public Health, Kilimanjaro Christian Medical University College, Moshi, Tanzania \\ ${ }^{3}$ Department of Nursing and Midwifery, School of Health and Medical Sciences, The State University of Zanzibar (SUZA), \\ Zanzibar, Tanzania \\ ${ }^{4}$ Kilimanjaro Christian Medical Centre, Department of Paediatric and Child Health, Moshi, Tanzania \\ ${ }^{5}$ Kilimanjaro Clinical Research Institute (KCRI), Moshi, Tanzania \\ ${ }^{6}$ Department of Obstetrics and Gynecology, Aarhus University Hospital, Aarhus, Denmark \\ Email: ‘rrbakar2012@yahoo.com,naeraheli@gmail.com, blaymt@gmail.com,birgitte.bruun.nielsen@dadlnet.dk
}

How to cite this paper: Bakar, R.R., Manongi, R.N., Mmbaga, B.T. and Nielsen, B.B. (2019) Perinatal Mortality and Associated Risk Factors among Singleton Babies in Unguja Island, Zanzibar. Health, 11, 91-107.

https://doi.org/10.4236/health.2019.111010

Received: October 17, 2018

Accepted: January 27, 2019

Published: January 30, 2019

Copyright $\odot 2019$ by author(s) and Scientific Research Publishing Inc. This work is licensed under the Creative Commons Attribution International License (CC BY 4.0).

http://creativecommons.org/licenses/by/4.0/ Open Access

\begin{abstract}
Background: Perinatal mortality is a major public health problem, particularly in developing countries where three quarters of neonatal deaths happen in the first week of life. Therefore, it is crucial to understand factors associated with perinatal mortality in order to design strategies and interventions that will improve newborn outcomes. Methods: A prospective cohort study was carried out, whereby pregnant women with gestational age $\geq 28$ weeks were enrolled. Interviews were conducted during antenatal booking using structured questionnaire. Follow-up visits were made within 48 hours after delivery and on seventh day post delivery. Results: A total of 959 pregnant women were enrolled; 38 were lost to follow-up prior delivery. The remaining 921 participants, resulting in PMR of 45.5 per 1000 births. Over half of the deaths were stillbirths (SBR 29.6 per 1000 births) and early neonatal deaths (ENMR 16.8 per 1000 live births). Using Generalized Linear Model (GLM), risk factors associated with perinatal mortality included: maternal age $\geq 35$ years (ARR 3.0, 95\% CI: 1.0 to 9.0), nulliparous women (ARR 4.2, 95\% CI: 1.6 to 11.1), assisted vaginal delivery (ARR 5.1, 95\% CI: 1.4 to 19.0), home delivery (ARR 3.3, 95\% CI: 1.6 to 6.6 ), previous newborn death (ARR 4.0, 95\% CI: 1.5 to 10.1), pregnancy-induced hypertension (ARR $4.8,95 \%$ CI: 2.4 to 9.4 ), herbal use during labour (ARR 2.4, 95\% CI: 1.2 to 5.1) and newborn asphyxia (ARR 5.9, 95\% CI: 1.3 to 26.5$)$. Conclusions: Perinatal mortality was found to be high in Zanzibar. Healthcare providers should pay special attention to women with pregnancy-induced hypertension and nulliparous women throughout
\end{abstract}


pregnancy and delivery. However, home delivery and use of herbs during labour should be discouraged.

\section{Keywords}

Perinatal Mortality, Stillbirth, Early Neonatal Death

\section{Introduction}

Perinatal mortality remains a major public health problem, particularly in developing countries. Globally, neonatal survival remains an urgent concern. It is unacceptable that about 16,000 children should still die every single day, which is equivalent to 11 deaths occurring every minute [1].

The first day and week are most critical for the survival of newborns. In 2013, almost 1 million newborns (36\%) died on the day they were born, another 1 million (37\%) died within the next six days of birth, and $27 \%$ of deaths occurred between Day 7 and Day 27 of life [2].

Child survival must remain at the heart of the post-2015 SDG agenda [1]. Tanzania is one among 63 countries which needs to accelerate progress to reach the SDG target of a neonatal mortality rate of 12 deaths per 1000 live births, by 2030 [1]; hence, the challenge of meeting this SDG target calls for more concerted efforts than ever before.

Tanzania is one of the ten countries contributing to the $66 \%$ of global neonatal deaths and $61 \%$ of global maternal deaths [3]. It is estimated that more than 1.6 million babies are born every year, and of these, while 51,000 die within the first month of life and 140 die each day, most from preventable causes. The perinatal mortality rate is higher in Tanzania Island (Zanzibar) than in Tanzania Mainland (49 deaths versus 39 deaths per 1000 live births, respectively) [4]. To compare the rate of neonatal and prenatal mortality between Tanzania and global statistics is very important. This will allow countries to review their achievements in the area of maternal and neonatal health and compare their results with those obtained by other countries. Also, it is crucial for countries to know the magnitude of neonatal and prenatal mortality in order to assess needs and develop programmes that will reduce avoidable child deaths more quickly.

The awareness situation in Zanzibar is similar to many other developing countries where little is known about perinatal mortality and its associated risk factors. A recent study conducted in Zanzibar reported perinatal mortality rate of 27 per 1000 live births [5].

Zanzibar has made specific attempts to address maternal and newborn health challenges through the adoption of the Safe Motherhood Initiative, which aims to reduce maternal, neonatal and child deaths. Despite such efforts, maternal and newborn mortality remain a leading public health problem [6]. This study aimed to address perinatal mortality in Zanzibar and to determine the associated risk factors which will help in designing the appropriate interventions that could 
be implemented to improve the survival of the newborn.

\section{Methods}

\subsection{Study Design}

A prospective cohort study to determine the perinatal mortality outcome was carried out in four out of the six districts in Unguja, from October 2014 to March 2015, in 16 randomly selected health facilities.

\subsection{Study Setting}

The semi-autonomous Islands of Zanzibar are located 40 kilometres east of Mainland Tanzania, in the Indian Ocean. Unguja Island is one of the two Islands in Zanzibar, the other being Pemba. Unguja Island has a total of six districts with a population of 896,721 , mostly concentrated in the Urban-West districts [7]. The Gross Domestic Product (GDP) of the Revolution Government of Zanzibar, Tanzania has spent a total of $5.3 \%$ as a contribution to health care system; however the allocated amount of funds is below compared to Abuja Declaration of $15 \%$. This resulted in weakening the health delivery system across all services in Zanzibar, Island including maternal, newborn and child health service delivery.

\section{Selection of Study Sites and Health Facilities}

Four districts were randomly selected for this study (North A, North B, West and Urban districts), which covered more than $50 \%$ of the population with urban and rural representation. Within each district, a random selection of health facilities was done; and eventually a total of sixteen of such facilities were selected all offering maternal and newborn health services.

\subsection{Study Population}

The study included pregnant women with gestational age $\geq 28$ weeks, attending antenatal care in the selected health facilities and those who consented to participate during the study period. Women who were eligible and enrolled for the study were those who agreed to deliver in Unguja Island and be followed-up for the entire study period. Women who were aged below 18 years and those who planned to deliver outside Unguja Island, Zanzibar were excluded in the study. Nine hundred and fifty nine (959) pregnant women were included, out of whom 921 (96.0\%) were followed-up until delivery, and 835 (87.07\%) were followed-up until seven days after delivery (Figure 1). Women were followed up for pregnancy outcome and survival of their newborns at 48 hours and at 7 th day after delivery.

\subsection{Pre-Testing and Validation of Questionnaires}

The research team organised a meeting and invited different stakeholders from Maternal, Newborn and Child Health $(\mathrm{MNCH})$ services to share and discuss the questionnaires in Kiswahili. Comments and input received, which were based on 


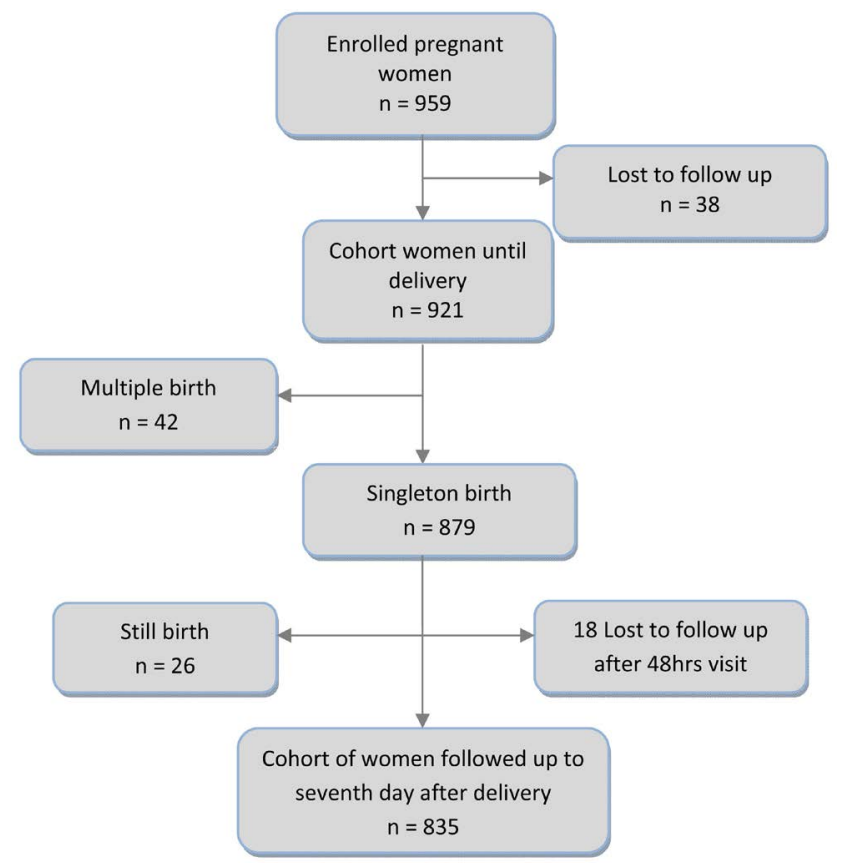

Figure 1. The characteristics and number of the study participants.

the existing practical situation at the $\mathrm{MNCH}$ services, were incorporated in the questionnaire which was later restructured to suit the local context. The English version of the questionnaire was also revised to capture the same content.

Secondly, pre-testing of the questionnaire was done to determine the validity and reliability of the responses. Pre-testing was conducted in four health facilities which were later dropped from the actual study. A total of twelve participants were involved for pretesting; each facility selected three respondents. The health facilities with high ANC and delivery services were selected purposively for piloting. After making the necessary corrections to the questionnaire, it was sent to the study sites.

\subsection{Data Collection Tools}

The study was conducted using a structured questionnaire, divided into three parts meant to collect information relating to three periods: Antenatal/ Pregnancy period (part one), Labour and Delivery (part two), and Postnatal period (part three). Part one was to collect information based on antenatal booking: previous and current pregnancy history, results of routine tests and examinations. It also included questions on demographic characteristics, social-cultural characteristics, maternal health status and social-economic characteristics. Part two collected information related to labour and delivery of the current pregnancy: onset of labour, type of delivery and delivery outcome. It also includes questions on obstetrical and gynaecological history, labour details, pregnancy outcomes and possible risk factors (maternal and newborn) for perinatal death. Part three collected information about the mother's and newborn's health status and care on the seventh day after delivery. 


\subsection{Data Collection Methods}

Before data collection started, the principal investigator conducted a three-day training for the selected research assistants from all health facilities involved in the study. The main focus of the training was to brief the assistants on the study, its objectives, the work schedule and logistics, research ethics and administrative issues. From each health facility one nursing officer experienced in doing research was recruited as a research assistant for the study and one research supervisor for each district.

Study participants were interviewed using three different questionnaires with structured questions, and which targeted different periods of reproduction. The first round of interviews took place during antenatal booking, the second round took place within 48 hours after delivery, and the last round was conducted on the $7^{\text {th }}$ day after delivery. The questionnaire administered at 48 hours and $7^{\text {th }}$ day included mostly the health conditions of the newborn, and on subsequent follow up. Study participants were followed-up throughout the pregnancy to the seventh day after delivery, to observe the outcome of the pregnancy. Figure 1 shows the characteristics and number of the study participants.

\subsection{Recruitment of Study Participants}

Sample size of the study was estimated by using EpiTools Epidemiological Calculators. Assuming relative risk of two with expected incidence rate of 27 deaths per 1000 births [5] at $95 \% \mathrm{CI}$ and power of $80 \%$, the minimum sample size was 833 women. The study also assumed $10 \%$ attrition rate, hence the enrolment of 959 women.

\section{First Interview: Data Collection during Antenatal Booking}

Women recruited at the antenatal clinic with a gestational age from $\geq 28$ weeks, were identified and recruited from the normal ANC system by using the same procedures used in these clinics to estimate the gestational age, using the last normal menstrual period (LNMP). The gestational age was calculated in weeks, based on the mentioned LNMP; however, a tape measure was also used to measure the fundal height by securing the tape measure at the fundus with one hand and then measuring from the top of the fundus to the top of the symphysis pubis. The finding was confirmed in line with the gestational age. All registered women were given an ID number and an open file. Data collection started when the study participant signed the consent form to participate in the study. Participants were asked to give their contact details such as phone number and physical address for better communication and follow-up during and after delivery. Information gathered during first round of interviews included maternal age, residence, pregnancy and delivery history (gravidity, parity, antenatal care, gestational age, fetal presentation, mode of previous delivery and obstetric and medical complications).

Second Interview: Data Collection within 48 Hours after Delivery

Research assistants traced the study participants through mobile phones and 
followed them up within 48 hours after delivery, regardless of where delivery took place-whether in a hospital or at home-based on the contact information given during recruitment. Each study participant was contacted three times throughout the study period: on the $32^{\text {nd }}$ week of the gestational age, during the documented expected date of delivery, and on the seventh day after delivery. However, a participant was required to call anytime she had a problem. Information gathered within 48 hours after delivery included labour and delivery information data was also extracted from the delivery notes using a structured questionnaire. Information on the newborn, including birth outcome, condition of the newborn, sex, weight and Apgar score were registered.

Third Interview: Data Collection on the Seventh Day after Delivery

Seventh day follow up mother and live baby at their home on the seventh day after delivery, to complete the information required on maternal and newborn health condition, including child status during early neonatal period; health baby, neonatal illness and early neonatal deaths.

\subsection{Statistical Analysis}

Data was analysed using SPSS 15.0 software. Categorical data was summarized using frequency, tables and percentages. Continuous variables were summarised using mode and mean. Descriptive analysis, frequencies, percentages and rates were calculated. Generalized Linear Model (GLM) was used for assessment of risk factors where univariate analysis was done. All factors with $\mathrm{P}$ value less than 0.05 in univariate analysis were considered for multivariable analysis in different steps to assess factors which remained as predictors of perinatal mortality. All categories with the lowest risk were used as a reference group in multivariable analysis. GLM was used so as to estimate directly the risk factors instead of odds ratio. 95\% confidence intervals (CIs) were estimated in models to determine the association between perinatal mortality and number of explanatory variables. A $P$ value of less than $<0.05$ was considered statistically significant.

\subsection{Ethical Considerations}

The study was approved by the Kilimanjaro Christian Medical University College Research and Ethical Review Committee (CRERC) with a certificate number 677. Permission to conduct the study was also obtained from the Zanzibar Research Council. A written informed consent was obtained from each study participant confirming willingness to participate in the study.

\section{Results}

\subsection{Characteristics of Study Participants}

A total of 959 pregnant women were enrolled in the study; the mean $( \pm S D)$ age was $29 \pm 6$ years ranging from 15 to 48 years. Half of the population was old or younger than 27 years. The majority (932) $97.2 \%$ of the participants were Muslim, with the following characteristics: married (915) 95.4\%, resident in urban 
area (788) $82.2 \%$, without formal employment (633) $66.8 \%$, and with secondary school or higher education (640) $66.7 \%$.

Of the enrolled women, $921(96.0 \%)$ were followed up through delivery (Figure 1). Of these, $95.4 \%$ delivered singleton babies, while those with multiple births (4.6\%) were excluded from the study. Of the 879 singleton births, $97 \%$ were alive at 48 hours, and $3 \%$ were stillborn. In the $7^{\text {th }}$ day follow up period after delivery, eighteen women could not be followed up, leaving a cohort of 835 ( $95 \%$ of singleton births) and 14 early neonatal deaths, leaving $98.3 \%$ live infants.

\subsection{Perinatal Mortality Estimation}

From 879 singleton births, 40 perinatal deaths (26 stillbirths, 14 early neonatal deaths) occurred resulting in a perinatal mortality rate of 45.5 per 1000 births of which stillbirth rate (SBR) was 29.6 per 1000 births and early neonatal mortality rate (ENMR) was 16.8 per 1000 live births.

\subsection{Risk Factors Associated with Perinatal Mortality \\ Socio-Demographic Characteristics of Women}

Maternal age below 20 years had a threefold increase risk for perinatal mortality compared to those aged 20 - 34 years (RR 2.9, 95\% CI: 1.0 to 8.0); however, after adjustment, the risk was not significant (Table 1). In multivariable analysis, perinatal mortality was 3 times higher in women $\geq 35$ years compared to 20 - 34 year old groups (ARR 3.0, 95\% CI: 1.0 to 9.0). Perinatal mortality was highest for mothers with no formal education (ARR 3.2, 95\% CI: 1.1 to 9.3) followed by mothers with primary education (ARR $2.3,95 \%$ CI: 1.0 to 5.3 ). Women with partners without formal education were at increased risk in unadjusted analysis (RR 3.7, 95\% CI: 1.7 to 8.4), but after adjustment, the risk was not significant. Other risk factors include nullipara women (ARR 4.2, 95\% CI: 1.6 to 11.1) and grand multipara women (RR 3.4, 95\% CI: 1.4 to 8.3), but after adjustment, the risk was not significant, residing in Urban district (ARR 3.2, 95\% CI: 1.6 to 6.6), and North A district (ARR 2.6, 95\% CI: 1.1 to 6.3). The associations between socio-demographic and perinatal mortality are presented in Table 1.

\section{Pregnancy Factors}

In univariate analysis, women who had registered for antenatal booking at the third trimester had increased risk of perinatal death (RR 2.8, 95\% CI: 1.1 to 7.1), but after adjustment, the risk was not significant. Using multivariable analysis women who attended antenatal clinic less than four times (ARR 5.2, 95\% CI: 2.4 to 11.0) had increased risk of their babies dying during the perinatal period. Also maternal conditions such as pregnancy induced hypertension (ARR 4.8, 95\% CI: 2.4 to 9.4 ) and previous newborn death (ARR $4.0,95 \%$ CI: 1.5 to 10.1 ) were associated with perinatal mortality. The associations between pregnancy and maternal conditions and perinatal mortality are presented in Table 2.

\section{Labour and Delivery Factors}

In multivariable analysis, women who delivered at home were more likely to experience perinatal mortality compared to those who delivered at a health facility 
Table 1. Socio-demographic and perinatal mortality among singletons $(\mathrm{N}=879)$.

\begin{tabular}{|c|c|c|c|c|}
\hline \multirow{2}{*}{ Risk Factor } & \multirow{2}{*}{ Total } & \multirow{2}{*}{$\begin{array}{c}\text { Perinatal Death } \\
\text { n (\%) }\end{array}$} & \multirow{2}{*}{$\mathrm{RR}(95 \% \mathrm{CI})$} & \multirow{2}{*}{$\operatorname{ARR}(95 \% \mathrm{CI})^{\#}$} \\
\hline & & & & \\
\hline \multicolumn{5}{|l|}{ Maternal age } \\
\hline$<20$ years & 43 & $4(9.3)$ & $2.9(1.0-8.0)$ & $1.3(0.4-3.8)$ \\
\hline 20 - 34 years & 652 & $21(3.2)$ & 1.0 & 1.0 \\
\hline$\geq 35$ years & 166 & $15(9.0)$ & $2.8(1.5-5.3)$ & $3.0(1.0-9.0)$ \\
\hline \multicolumn{5}{|l|}{ Maternal education } \\
\hline No formal education & 67 & $9(13.4)$ & $4.7(2.2-10.1)$ & $3.2(1.1-9.3)$ \\
\hline Primary education & 200 & $14(7.0)$ & $2.4(1.2-4.9)$ & $2.3(1.0-5.3)$ \\
\hline Secondary \& above & 594 & $17(2.9)$ & 1.0 & 1.0 \\
\hline \multicolumn{5}{|l|}{ Partner education } \\
\hline No formal education & 57 & $7(12.3)$ & $3.7(1.7-8.4)$ & $1.8(0.6-5.3)$ \\
\hline Primary education & 168 & $12(7.1)$ & $2.2(1.1-4.3)$ & $1.4(0.6-3.2)$ \\
\hline Secondary \& above & 636 & $21(3.3)$ & 1.0 & 1.0 \\
\hline \multicolumn{5}{|l|}{ Parity } \\
\hline Nullipara (0) & 216 & $15(6.9)$ & $2.6(1.2-5.9)$ & $4.2(1.6-11.1)$ \\
\hline Primapara (1) & 198 & $6(3.0)$ & $1.1(0.4-3.2)$ & $1.8(0.6-5.2)$ \\
\hline Multipara (2 - 4) & 338 & $9(2.7)$ & 1.0 & 1.0 \\
\hline Grandmultipara (5+) & 109 & $10(9.2)$ & $3.4(1.4-8.3)$ & $1.2(0.4-3.6)$ \\
\hline \multicolumn{5}{|l|}{ District of residence } \\
\hline West district & 525 & $13(2.5)$ & 1.0 & 1.0 \\
\hline Urban district & 183 & $14(7.7)$ & $3.1(1.5-6.4)$ & $3.2(1.6-6.6)$ \\
\hline North A district & 80 & $10(12.5)$ & $5.0(2.3-11.1)$ & $2.6(1.1-6.3)$ \\
\hline North B district & 73 & $3(4.1)$ & $1.7(0.5-5.7)$ & $1.5(0.4-5.6)$ \\
\hline
\end{tabular}

"ARR has been adjusted to maternal age, maternal education, partner education, parity and maternal residence. $\mathrm{ARR}=$ Adjusted RR; $\mathrm{CI}=$ Confidence Interval; $\mathrm{RR}=$ Relative Risk.

Table 2. Pregnancy and maternal conditions associated with perinatal mortality among singletons $\left(\mathrm{N}=879^{*}\right)$.

\begin{tabular}{|c|c|c|c|c|}
\hline \multirow{2}{*}{ Factor } & \multirow{2}{*}{ Total } & Perinatal death & \multirow{2}{*}{$\mathrm{RR}(95 \% \mathrm{CI})$} & \multirow{2}{*}{$\operatorname{ARR}(95 \% \mathrm{CI})^{\#}$} \\
\hline & & n (\%) & & \\
\hline \multicolumn{5}{|c|}{ Time for ANC booking } \\
\hline $1^{\text {st }}$ trimester & 208 & $8(3.8)$ & 1.0 & 1.0 \\
\hline $2^{\text {nd }}$ trimester & 578 & $24(4.2)$ & $1.1(0.5-2.4)$ & $1.8(0.2-13.1)$ \\
\hline $3^{\text {rd }}$ trimester & 75 & $8(10.7)$ & $2.8(1.1-7.1)$ & $7.0(0.7-67.5)$ \\
\hline \multicolumn{5}{|l|}{ Attended prenatal care } \\
\hline$>4$ times & 637 & $26(4.1)$ & 1.0 & 1.0 \\
\hline$<4$ times & 140 & $14(10.0)$ & $2.5(1.3-4.6)$ & $5.2(2.4-11.0)$ \\
\hline
\end{tabular}




\section{Continued}

Previous abortion

$\begin{array}{ccccc}\text { Yes } & 188 & 14(7.4) & 2.7(1.3-5.7) & 1.6(0.6-4.7) \\ \text { No } & 477 & 13(2.7) & 1.0 & 1.0\end{array}$

Previous newborn death

$\begin{array}{lcccc}\text { Yes } & 101 & 10(9.9) & 4.6(2.0-10.5) & 4.0(1.5-10.1) \\ \text { No } & 508 & 11(2.2) & 1.0 & 1.0 \\ \text { diabetes } & & & & \\ \text { Yes } & 23 & 4(17.4) & 3.8(1.5-9.9) & 1.7(0.6-5.1) \\ \text { No } & 794 & 36(4.5) & 1.0 & 1.0\end{array}$

Pregnancy induced

hypertension (PIH)

$\begin{array}{lcccc}\text { Yes } & 50 & 8(16.0) & 4.0(1.9-8.1) & 4.8(2.4-9.4) \\ \text { No } & 790 & 32(4.1) & 1.0 & 1.0\end{array}$

Pre-eclampsia

Yes

$3.0(1.1-7.8)$

$4.2(0.6-30.0)$

No

802

$36(4.5)$

1.0

1.0

Use of iron tablet

$\begin{array}{lllcc}\text { Yes } & 407 & 12(2.9) & 1.0 & 1.0 \\ \text { No } & 454 & 28(6.2) & 2.1(1.1-4.1) & 0.8(0.0-15.2)\end{array}$

Use of folic acid tablet

\begin{tabular}{ccccc} 
Yes & 395 & $10(2.5)$ & 1.0 & 1.0 \\
No & 466 & $30(6.4)$ & $2.5(1.3-5.1)$ & $1.9(0.1-38.7)$ \\
\hline
\end{tabular}

"ARR has been adjusted to time for ANC booking, attendance of prenatal care, previous abortion, previous newborn death, gestation diabetes, PIH, pre-eclampsia, use of iron tablets and use of folic tablets. ARR = Adjusted RR; CI = Confidence Interval; RR = Relative Risk. ${ }^{*}$ Not all participants had all categories information available in each variable so the total in some variables may not make to 879 .

(ARR 3.3, 95\% CI: 1.6 to 6.6 ). Again, perinatal mortality was highest in mothers who had assisted deliveries by instruments compared to mothers delivering spontaneously (ARR 5.1, 95\% CI: 1.4 to 19.0). Women who used herbs during labour were almost three times at risk for perinatal mortality (ARR 2.4, 95\% CI: 1.2 to 5.1 ). The associations between labour and delivery factors and perinatal mortality are presented in Table 3.

\section{Newborn Factors}

Using multivariable analysis, newborn factors associated with perinatal mortality included neonatal asphyxia (ARR 5.9, 95\% CI: 1.3 to 26.5). In univariate analysis, low birth weight (RR 2.5; 95\% CI 1.1 to 6.0 ), and unable to breast-feed after delivery (RR 3.2, 95\% CI: 1.0 to 9.9). However, in adjusted analysis inability to breast feed and low birth weight were not significant; instead, high birth weight (ARR 3.1, 95\% CI: 1.0 to 9.2) was associated with perinatal death in adjusted analysis. The associations between newborn factors and perinatal mortality are presented in Table 4. 
Table 3. Labour and delivery factors associated with perinatal mortality among singletons $\left(\mathrm{N}=879^{\star}\right)$.

\begin{tabular}{|c|c|c|c|c|}
\hline \multirow{2}{*}{ Factor } & \multirow{2}{*}{ Total } & \multirow{2}{*}{$\begin{array}{c}\text { Perinatal Death } \\
\mathrm{n}(\%)\end{array}$} & \multirow{2}{*}{ RR (95\% CI) } & \multirow{2}{*}{$\operatorname{ARR}(95 \% \mathrm{CI})^{\#}$} \\
\hline & & & & \\
\hline \multicolumn{5}{|l|}{ Place of delivery } \\
\hline Hospital & 727 & $27(3.7)$ & 1.0 & 1.0 \\
\hline Home & 134 & $13(9.7)$ & $2.6(1.4-4.9)$ & $3.3(1.6-6.6)$ \\
\hline \multicolumn{5}{|l|}{ Mode of delivery } \\
\hline Vaginal & 759 & $30(4.0)$ & 1.0 & 1.0 \\
\hline Caesarean section & 72 & $7(9.7)$ & $2.5(1.1-5.4)$ & $5.1(0.5-46.9)$ \\
\hline Assisted vaginal & 20 & $3(15.0)$ & $3.8(1.3-11.4)$ & $5.1(1.4-19.0)$ \\
\hline \multicolumn{5}{|l|}{ Birth attendant } \\
\hline Nurse midwife & 639 & $19(3.0)$ & 1.0 & 1.0 \\
\hline Physician & 80 & $8(10.0)$ & $0.3(0.1-0.7)$ & $0.4(0.0-4.5)$ \\
\hline Traditional birth attendant (TBA) & 134 & $13(9.7)$ & $1.0(0.4-2.2)$ & $1.0(0.0-0.0)$ \\
\hline \multicolumn{5}{|l|}{ Obstructed labour } \\
\hline Yes & 37 & $6(16.2)$ & $3.7(1.7-8.2)$ & $2.6(0.6-10.3)$ \\
\hline No & 775 & $34(4.4)$ & 1.0 & 1.0 \\
\hline \multicolumn{5}{|l|}{ Use of herbs in labour } \\
\hline Yes & 61 & $8(13.1)$ & $3.1(1.5-6.4)$ & $2.4(1.2-5.1)$ \\
\hline No & 756 & $32(4.2)$ & 1.0 & 1.0 \\
\hline
\end{tabular}

"ARR has been adjusted to place of delivery, mode of delivery, birth attendant, obstructed labour and herbal use during labour. $\mathrm{ARR}=$ Adjusted $\mathrm{RR} ; \mathrm{CI}=$ Confidence Interval; $\mathrm{RR}=$ Relative Risk. ${ }^{*}$ Not all participants had all categories information available in each variable so the total in some variables may not make to 879 .

Table 4. Newborn factors associated with perinatal mortality among singletons $(\mathrm{N}=$ $\left.835^{\star}\right)$.

\begin{tabular}{|c|c|c|c|c|}
\hline \multirow{2}{*}{ Factor } & \multirow{2}{*}{ Total } & \multirow{2}{*}{$\begin{array}{c}\text { Perinatal Death } \\
\mathrm{n}(\%)\end{array}$} & \multirow{2}{*}{ RR $(95 \% \mathrm{CI})$} & \multirow{2}{*}{$\operatorname{ARR}(95 \% \mathrm{CI})^{\#}$} \\
\hline & & & & \\
\hline \multicolumn{5}{|l|}{ Sex } \\
\hline Female & 402 & $16(4.0)$ & 1.0 & 1.0 \\
\hline Male & 459 & $24(5.2)$ & $1.3(0.7-2.4)$ & $1.4(0.4-4.9)$ \\
\hline \multicolumn{5}{|c|}{ Weight of newborn } \\
\hline Normal & 608 & $22(3.6)$ & 1.0 & 1.0 \\
\hline Small & 66 & $6(9.1)$ & $2.5(1.1-6.0)$ & $0.6(0.1-4.1)$ \\
\hline Large & 73 & $6(8.2)$ & $2.3(0.1-5.4)$ & $3.1(1.0-9.2)$ \\
\hline \multicolumn{5}{|c|}{ Newborn asphyxia } \\
\hline Yes & 49 & $9(18.4)$ & $4.3(2.2-8.4)$ & $5.9(1.3-26.5)$ \\
\hline No & 720 & $31(4.3)$ & 1.0 & 1.0 \\
\hline \multicolumn{5}{|c|}{ Able to breastfeed } \\
\hline Yes & 536 & $10(1.9)$ & 1.0 & 1.0 \\
\hline No & 67 & $4(6.0)$ & $3.2(1.0-9.9)$ & $2.2(0.6-8.8)$ \\
\hline
\end{tabular}




\section{Discussion}

\subsection{Perinatal Mortality Estimation}

This study aimed at estimating perinatal death in Zanzibar and associated risk factors. The PMR found was high (45.5 per 1000 births), compared to a recent study done in Zanzibar by Lund et al. which reported a perinatal mortality rate (PMR) of 27 per 1000 births [5]. However, in comparing the results of this study to similar prospective studies in North-eastern Tanzania, our findings show that PMR was lower compared to 52 per 1000 births [8], and 57.7 per 1000 births [9]. The lower PMR reported by Lund et al. might be due to the intervention done using SMS mobile in following mothers during pregnancy and neonatal care period. The high PMR by Mmbaga et al. might be due to the fact that the hospital is a tertiary care hospital with high referral cases referred due to complications; this was also indicated by their study having twice PMR in referred cases [9].

In this study, high rates of stillbirth were found, accounting for almost two thirds of perinatal deaths and this was similar to a study conducted at Kilimanjaro Christian Medical Centre (KCMC) [9] and in Tanga Region, Tanzania by Schmiegelow in which stillbirth was almost half of perinatal deaths [8]; the different in a former study might be due to the close follow-up and care given to pregnant women during the study period in Tanga. In this study, we observed a marked variation in perinatal mortality between districts, ranging from 24.8 per 1000 births in the West District to 125 per 1000 births in North A District. Differences might be due to the low socio-economic and education status, higher parity and preference of home delivery of study participants in North A District. These findings have important implications for maternal and newborn stakeholders and policy makers in the reduction of perinatal mortality in Zanzibar.

\subsection{Maternal Age}

Maternal young age was a significant factor for perinatal mortality but the risk decreased after adjustment; however, for advanced maternal age the risk remained throughout all steps of adjustment. Mothers of both age extremes of reproductive age carry greater risks for adverse pregnancy outcomes compared with those between 20 and 34 years. Advanced maternal age $\geq 35$ is well known to increase the risk for perinatal complications and adverse pregnancy outcomes, compared to younger women; however, teenage deliveries also carry risk for perinatal death [10] [11] [12]. Similar to our findings, a study at Muhimbili National Hospital found that advanced maternal age was associated with poorer pregnancy outcome, a higher incidence of prenatal complications and higher incidences stillbirths and maternal mortality [11]. The risk might be linked to the fact that advanced maternal age has been associated with increased risk of medical complications as well as poor placental circulation.

\subsection{Parity}

Similar to older age women, nulliparous women remained a significant factor in 
all steps after adjusting for other factors. Despite having a higher confident interval it was still an important predictor of perinatal death. Several studies provided similar results supporting primiparity as a significant risk factor [13]. In a similar study done in Sudan, primiparity was associated with neonatal mortality [14]. A study in Uganda found that perinatal mortality among nulliparous women was 3.3 times higher than in women who had given birth to a live baby in a prior pregnancy [13]. In addition, one study showed that nulliparous women of $<18$ years have the highest odds of adverse neonatal outcomes in general [15]. Women in developing countries generally tend to have many pregnancies [16] and research provides conflicting views about whether increasing parity increases the risk of perinatal mortality. Previous studies demonstrated that maternal parity $>4$ [17] [18] was significantly associated with perinatal mortality and newborn deaths, respectively. A study done in Zimbabwe found the risk of obstetric complications and hence perinatal mortality increased with increasing parity [17]. In contrast, in Uganda, increasing parity had a lower risk for mortality, though not statistically significant [19].

\subsection{District of Residence}

In this study, women residing in Urban and Rural (North A and B) districts had higher perinatal mortality than women living in West District (urban). Using univariate analysis, women who resided in rural areas had a $34 \%$ increased risk of perinatal mortality compared to those living in urban areas. Living in rural areas can be a risk for pregnant women since quality health services and infrastructure are usually more accessible in urban centres. Similar to our study, the meta-analysis done on developing countries showed that perinatal mortality was significantly higher in rural areas [20]. In Tanzania, a demographic health survey which was conducted in 2010 found that both women living in urban areas as well as in rural areas have increased risk of perinatal death [21]. Our findings might have been influenced by the high number of referrals for pregnant women with complications from other districts of Zanzibar to the urban health facilities which might play a role in poor perinatal outcomes.

\subsection{Previous Newborn Death}

In this study, women with a history of previous newborn deaths had twice as much the risk of perinatal mortality than those with previous live births. This is in line with a birth registry study at KCMC which showed that women who lost a child in their first pregnancy had higher risk of perinatal death with a subsequent pregnancy than women with a surviving child [22]. Another study in Dar es Salaam involving women with a history of previous adverse pregnancy outcome were two times more likely to have a perinatal death than those who had a history of a live baby [23]. Women with a previous perinatal mortality had a greater risk of perinatal death in a subsequent pregnancy [22]. The complication from previous pregnant might play a role in subsequent pregnancy if no proper care and management is undertaken. Therefore, women with previous newborn 
deaths need to be identified early as high risks mothers during antenatal visit, and close follow up and supervision could help in saving the newborn's life. The wired mother study conducted in Zanzibar noted that close follow up and communication with pregnant women decreased the perinatal deaths [5]. Babies who were born to women who had a previous history of losing their baby to perinatal death during their last pregnancy showed higher odds of perinatal death than their counterparts [24].

\subsection{Pregnancy-Induced Hypertension}

In this study, women with hypertension during pregnancy were almost ten times more likely to experience perinatal mortality than those without. This finding concurs with previous studies which found that pregnancy-induced hypertension and ante partum haemorrhage increase the risk of stillbirths and perinatal mortality [25]. Ante-partum haemorrhage is usually caused by placenta abruption which results in stillbirth [17] as a result of pregnant-induced hypertension. There might be multiple etiologic factors that affect foetal survival in relation to hypertension. This further emphasises the importance of quality antenatal and intrapartum care, and early attendance of ANC clinic for early detection and prompt management of maternal medical conditions including hypertensive disorders.

\subsection{Place of Delivery}

In this study, one of the most important factors for perinatal mortality was the place of delivery. Perinatal mortality was higher for women who delivered at home compared to women who delivered in health facilities. This might be influenced by social-economical factors as women needed to buy some of the equipment needed for delivery. Moreover, experience of non-complicated delivery at home, might influence some women to overlook the importance of delivering at a health facility. These findings are similar to findings from other studies; for example, in a meta-analysis study in Sub-Saharan Africa, perinatal mortality rate was significantly higher for home delivery compared to delivery in a facility [26]. In a study carried out in Zimbabwe, women who delivered at home were more likely to experience perinatal mortality, and home deliveries were often conducted by untrained birth attendants in unsanitary conditions [17]. In addition, a study conducted in Ethiopian found that mothers residing in urban areas were 3.3 times more likely to give birth in a health facility than mothers residing in rural areas [27]. In Zanzibar, the practice of home delivery is still common, increasing the risk of perinatal mortality which may be linked to lack of skilled care including resuscitation skills. Efforts to convince women to deliver at a health facility need to be continued on all levels particularly for women at high risk.

\subsection{Use of Herbs in Labour}

This study found that women who had used herbs during labour were more likely to have perinatal mortality than those who didn't use them in multivari- 
able analysis. A previous study revealed that pregnant and delivering women commonly use herbs to gain therapeutic effects which may be beneficial in easing the labour process without any side effects to mother and baby [28]. In Kenya, about $12 \%$ of women used herbs during their most recent pregnancy [29]. A study in Tanzania found out that traditional medicines given by traditional providers were used in almost half the number of women who experienced unsafe abortion. Of the 21 plant species identified and analysed as abortion-inducing, 16 had effect on uterine contraction by significantly increasing the force and/or frequency of contractions [30]. Some women might use these medicines during labour with adverse effects. Until definitive data is put together, the best practice is to consider all herbal medicine products unsafe during pregnancy and lactation, and to advise patients accordingly [31]. Use of traditional medicine during labour was found to be very common in many pregnant women, and the adverse effects to the newborn are significantly high. Therefore, there is need to educate pregnant women during antenatal care attendance on the adverse outcomes of such practices to the health and survival of the newborn.

\subsection{Newborn Factors}

\section{Newborn Asphyxia}

In this study, we found out that a newborn with asphyxia at birth had an almost $30 \%$ higher risk of perinatal mortality compared to infants delivered in normal vaginal delivery. Birth asphyxia is a major cause of neonatal death as reported in many studies, in Northern Tanzania [32], Kenya [33], Uganda [18], and India [34]. As the study reported, nearly two thirds of perinatal mortality were fresh stillbirths-deaths that might have been due to asphyxia. Hence, the knowledge and practice of health care providers about the immediate care that they give to newly born babies including resuscitation, need to be checked and improved to ensure survival of the newborn.

\section{Conclusion}

The study showed that there was high perinatal mortality compared to overall perinatal mortality of 27 per 1000 total births reported in a cluster-randomised trials study, conducted in 2014, in Zanzibar. The most significant risk factors associated with perinatal mortality in this study were maternal age 35 years and above, nulliparous women, pregnancy induced hypertension, home delivery, assisted vaginal delivery, previous new born death, new born asphyxia and use of herbs during labour. Therefore, to reduce the burden of perinatal mortality, early identification and prompt management of risk factors during pregnancy and labour are paramount, and women should be strongly advised to deliver in a formal health facility.

\section{Conflicts of Interest}

The authors declare that they have no competing interests. 


\section{References}

[1] United Nations Inter-Agency Group for Child Mortality Estimation (UN IGME) (2015) Levels \& Trends in Child Mortality. Report 2015. United Nations Children's Fund, New York.

[2] United Nations Inter-Agency Group for Child Mortality Estimation (UN IGME) (2014) Levels \& Trends in Child Mortality. Report 2014. United Nations Children's Fund, New York.

[3] Ministry of Health and Social Welfare (2008) The National Road Map Strategic Plan to Accelerate Reduction of Maternal, Newborn and Child Deaths in Tanzania 2008-2015. Ministry of Health and Social Welfare, Dar es Salaam.

[4] National Bureau of Statistics and ICF Macro (2016) Tanzania Demographic and Health Survey and Malaria Indicator Survey (TDHS-MIS) 2015-16. National Bureau of Statistics and ICF, Dar es Salaam.

[5] Lund, S., Rasch, V., Hemed, M., Boas, I.M., Said, A., Said, K., et al. (2014) Mobile Phone Intervention Reduces Perinatal Mortality in Zanzibar: Secondary Outcomes of a Cluster Randomized Controlled Trial. Journal of Medical Internet Research-JMIR Mhealth Uhealth, 2, e15. https://doi.org/10.2196/mhealth.2941

[6] Ministry of Health and Social Welfare (MoHSW) (2008) Road Map to Accelerate the Reduction of Maternal, Newborn and Child Mortality in Zanzibar (2008-2015). Ministry of Health and Social Welfare, Zanzibar.

[7] National Bureau of Statistics (NBS) (2013) The 2012 Population and Housing Census, Age and Sex Distribution Report. National Bureau of Statistics, Dar es Salaam.

[8] Schmiegelow, C., Minja, D., Oesterholt, M., Pehrson, C., Suhrs, H.E., Bostrom, S., et al. (2012) Factors Associated with and Causes of Perinatal Mortality in Northeastern Tanzania. Acta Obstetricia et Gynecologica Scandinavica, 91, 1061-1068. https://doi.org/10.1111/j.1600-0412.2012.01478.x

[9] Mmbaga, B.T., Lie, R.T., Olomi, R., Mahande, M.J., Olola, O. and Daltveit, A.K. (2012) Causes of Perinatal Death at a Tertiary Care Hospital in Northern Tanzania 2000-2010 : A Registry Based Study. BMC Pregnancy Childbirth, 12, 139.

[10] Yerebasmaz, N., Akdag, D.C., Özdemirci, Ş., Erturk, S. and Kayikcioglu, F. (2016) Does Advanced Maternal Age Increase the Risk of Adverse Perinatal Outcomes? Acta Medica, 5, 23-29.

[11] Muganyizi, P.S. and Balandya, B. (2013) Pregnancy Outcomes in the Extremes of Reproductive Age: A Seven-Year Experience in Tanzania. Open Journal of Obstetrics and Gynecology, 3, 51-57. https://doi.org/10.4236/ojog.2013.31012

[12] Mutz-Dehbalaie, I., Scheier, M., Jerabek-Klestil, S., Brantner, C., Windbichler, G.H., Leitner, H., et al. (2014) Perinatal Mortality and Advanced Maternal Age. Gynecologic and Obstetric Investigation, 77, 50-57. https://doi.org/10.1159/000357168

[13] Nankabirwa, V., Tumwine, J.K., Tylleskär, T., Nankunda, J. and Sommerfelt, H. (2011) Perinatal Mortality in Eastern Uganda: A Community Based Prospective Cohort Study. PLoS ONE, 6, e0019674. https://doi.org/10.1371/journal.pone.0019674

[14] Bashir, A.O., Ibrahim, G.H., Bashier, I.A. and Adam, I. (2013) Neonatal Mortality in Sudan : Analysis of the Sudan Household Survey, 2010. BMC Public Health, 13, 287. https://doi.org/10.1186/1471-2458-13-287

[15] Kozuki, N., Lee, A.C.C., Silveira, M.F., Sania, A., Vogel, J.P., Adair, L., et al. (2013) The Associations of Parity and Maternal Age with Small-for-Gestational-Age, Preterm, and Neonatal and Infant Mortality: A Meta-Analysis. BMC Public Health, 13, 
S2. https://doi.org/10.1186/1471-2458-13-S3-S2

[16] Onwudiegwu, U. and Awowole, I. (2012) Current Trends in Perinatal Mortality in Developing Countries: Nigeria as a Case Study, Perinatal Mortality.

https://doi.org/10.5772/32328

https://www.intechopen.com/books/perinatal-mortality/current-trends-in-perinatal -mortality-in-developing-countries-nigeria-as-a-case-study

[17] Tachiweyika, E., Gombe, N., Shambira, G., Chadambuka, A., Mufuta, T., Zizhou, S., et al. (2011) Determinants of Perinatal Mortality in Marondera District, Mashonaland East Province of Zimbabwe, 2009: A Case Control Study. Pan African Medical Journal, 8, 7. https://doi.org/10.4314/pamj.v8i1.71054

[18] Nakimuli, A., Mbalinda, S.N., Nabirye, R.C., Kakaire, O., Nakubulwa, S., Osinde, M.O., et al. (2015) Still Births, Neonatal Deaths and Neonatal near Miss Cases Attributable to Severe Obstetric Complications: A Prospective Cohort Study in Two Referral Hospitals in Uganda. BMC Pediatrics, 15, 44.

[19] Musooko, M., Kakaire, O., Nakimuli, A., Nakubulwa, S., Nankunda, J., Osinde, M.O., et al. (2014) Incidence and Risk Factors for Early Neonatal Mortality in Newborns with Severe Perinatal Morbidity in Uganda. International Journal of $G y$ necology \& Obstetrics, 127, 201-205. https://doi.org/10.1016/j.ijgo.2014.05.017

[20] Berhan, Y. and Berhan, A. (2014) A Meta-Analysis of Social-Demographic Factors for Perinatal Mortality in Developing Countries: A Subgroup Analysis of the National Surveys and Small Scale Studies. Ethiopian Journal of Health Scie, 24, 41-54. https://doi.org/10.4314/ejhs.v24i0.5S

[21] National Bureau of Statistics and ICF Macro (2011) Tanzania Demographic and Health Survey 2010. National Bureau of Statistics and ICF Macro, Dar es Salaam.

[22] Mahande, M.J., Daltveit, A.K., Mmbaga, B.T., Obure, J., Masenga, G., Manongi, R., et al. (2013) Recurrence of Perinatal Death in Northern Tanzania: A Registry Based Cohort Study. BMC Pregnancy Childbirth, 13, 166.

https://doi.org/10.1186/1471-2393-13-166

[23] Mpembeni, R., Jonathan, R. and Mughamba, J. (2014) Perinatal Mortality and Associated Factors among Deliveries in Three Municipal Hospitals of Dar Es Salaam, Tanzania. Journal of Pediatrics and Neonatal Care, 1, 4.

[24] Yirgu, R., Molla, M., Sibley, L. and Gebremariam, A. (2016) Perinatal Mortality Magnitude, Determinants and Causes in West Gojam: Population-Based Nested Case-Control Study. PLoS ONE, 11, e0159390. https://doi.org/10.1371/journal.pone.0159390

[25] Allanson, E., Muller, M. and Pattinson, R. (2015) Causes of Perinatal Mortality and Associated Maternal Complications in a South African Province: Challenges in Predicting Poor Outcomes. BMC Pregnancy Childbirth, 15, 37.

https://doi.org/10.1186/s12884-015-0472-9

[26] Chinkhumba, J., Allegri, M., Muula, A. and Robberstad, B. (2014) Maternal and Perinatal Mortality by Place of Delivery in Sub-Saharan Africa: A Meta-Analysis of Population-Based Cohort Studies. BMC Public Health, 14, 1014. https://doi.org/10.1186/1471-2458-14-1014

[27] Habte, F. and Demissie, M. (2015) Magnitude and Factors Associated with Institutional Delivery Service Utilization among Childbearing Mothers in Cheha District, Gurage Zone, SNNPR, Ethiopia: A Community Based Cross Sectional Study. BMC Pregnancy Childbirth, 15, 299. https://doi.org/10.1186/s12884-015-0716-8

[28] Ramasubramaniam, S., Renganathan, L., Vijayalakshmi, G. and Mallo-Banatao, M. (2015) Use of Herbal Preparations among Parturient Women: Is There Enough 
Evidence-A Review of Literature. International Journal of Herbal Medicine, 2, 20-26.

[29] Mothupi, M. (2014) Use of Herbal Medicine during Pregnancy among Women with Access to Public Healthcare in Nairobi, Kenya: A Cross-Sectional Survey. BMC Complementary and Alternative Medicine, 14, 432.

https://doi.org/10.1186/1472-6882-14-432

[30] Rasch, V., Sørensen, P., Wang, A., Tibazarwa, F. and Jäger, A. (2014) Unsafe Abortion in Rural Tanzania-The Use of Traditional Medicine from a Patient and a Provider Perspective. BMC Pregnancy Childbirth, 14, 419.

[31] Ernst, E. (2002) Herbal Medicinal Products during Pregnancy: Are They Safe? BJOG: An International Journal of Obstetrics \& Gynaecology, 109, 227-235. https://doi.org/10.1111/j.1471-0528.2002.t01-1-01009.x

[32] Mmbaga, B.T., Lie, R.T., Olomi, R., Mahande, M.J., Kvåle, G. and Daltveit, A.K. (2012) Cause-Specific Neonatal Mortality in a Neonatal Care Unit in Northern Tanzania: A Registry Based Cohort Study. BMC Pediatrics, 12, 116. https://doi.org/10.1186/1471-2431-12-116

[33] Yego, F., Williams, J.S., Byles, J., Nyongesa, P., Aruasa. W. and D’Este, C. (2013) A Retrospective Analysis of Maternal and Neonatal Mortality at a Teaching and Referral Hospital in Kenya. Reproductive Health, 10, 13.

[34] Siddalingappa, H., Murthy, N., Kulkarni, P. and Ashok, N. (2013) Prevalence and Factors Influencing Perinatal Mortality in Rural Mysore, India. Journal of Clinical and Diagnostic Research, 7, 2796-2799. 